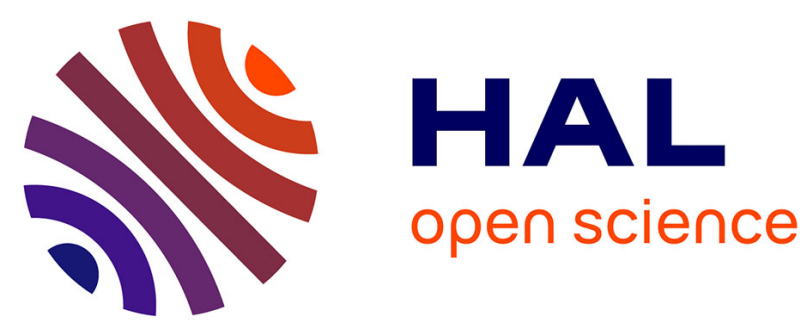

\title{
A comparison of different approaches for the modelling of shallow foundations in seismic soil-structure interaction problems
}

Stéphane Grange, D. Salciarini, Panagiotis Kotronis, Claudio Tamagnini

\section{To cite this version:}

Stéphane Grange, D. Salciarini, Panagiotis Kotronis, Claudio Tamagnini. A comparison of different approaches for the modelling of shallow foundations in seismic soil-structure interaction problems. NUMGE 2010, 7th International Conference on Numerical Methods in Geotechnical Engineering, Jun 2010, Trondheim, Norway. hal-01007726

\section{HAL Id: hal-01007726 \\ https://hal.science/hal-01007726}

Submitted on 5 Nov 2019

HAL is a multi-disciplinary open access archive for the deposit and dissemination of scientific research documents, whether they are published or not. The documents may come from teaching and research institutions in France or abroad, or from public or private research centers.
L'archive ouverte pluridisciplinaire HAL, est destinée au dépôt et à la diffusion de documents scientifiques de niveau recherche, publiés ou non, émanant des établissements d'enseignement et de recherche français ou étrangers, des laboratoires publics ou privés. 


\title{
A comparison of different approaches for the modelling of shallow foundations in seismic soil-structure interaction problems
}

\author{
Stéphane Grange ${ }^{1}$, Diana Salciarini ${ }^{2}$, Panagiotis Kotronis ${ }^{3}$ \& Claudio Tamagnini ${ }^{2}$ \\ ${ }^{1}$ Laboratoire 3S-R, UJF, INPG, CNRS, Grenoble, France \\ ${ }^{2}$ University of Perugia, Perugia, Italy \\ ${ }^{3}$ Institut GeM, Ecole Centrale de Nantes, UMR CNRS 6183, Nantes, France
}

\begin{abstract}
In this work, the performance of two different macroelement models for shallow foundations on sands is assessed by considering the dynamic response of a $\mathrm{RC}$ bridge subject to earthquake loading. The first macroelement model is formulated within the framework of kinematic hardening elastoplasticity with prescribed bounding surface (Grange et al. 2009). The second macroelement model has been recently developed within the framework of the theory of hypoplasticity (Salciarini and Tamagnini 2009). The results of a series of FE simulations show that a significant reduction of the computed structural loads can be obtained by taking properly into account the foundation-soil behavior, rather than assuming zero displacements and rotations at the pier bases. The two macroelements considered provide quite similar results, in spite of the large differences existing in their mathematical formulation.
\end{abstract}

\section{INTRODUCTION}

Recent developments in the analysis of the seismic response of slender structures such as tall buildings and bridge piers resting on shallow foundations have shown that the proper consideration of soil deformability is of primary importance for an accurate prediction of the deformation and loads experienced by the structure during the earthquake, see, e.g., (Grange et al. 2009).

A substantial progress towards an efficient and reliable approach to the analysis of soil-foundationstructure interaction (SFSI) problems for such kind of structures has been recently achieved by the development of the so-called macroelement models for describing the overall behavior of the foundation-soils system (see, e.g., Nova and Montrasio 1991, Martin and Houlsby 2001, Crémer et al. 2001). In the macroelement approach, the mechanical response of the foundation-soil system is described by means of a constitutive equation relating the generalized load vector:

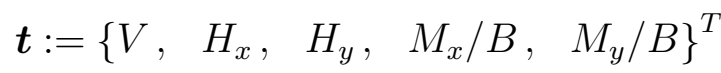

and the generalized displacement vector:

$$
\boldsymbol{u}:=\left\{w, \quad u_{x}, \quad u_{y}, \quad \theta_{x} B, \quad \theta_{y} B\right\}^{T}
$$

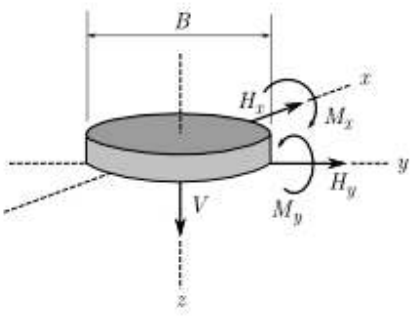

(a)

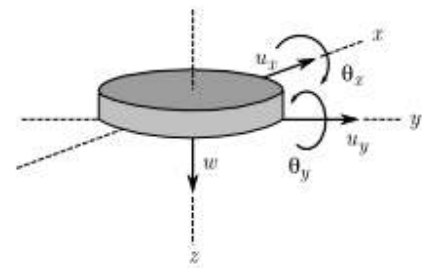

(b)
Figure 1: Notation adopted for generalized forces (a) and displacement (b) components.

In the above definitions, $V, H_{x}, H_{y}, M_{x}$ and $M_{y}$ are the resultant forces and moments acting on the foundation; $w, u_{x}, u_{y}, \theta_{x}$ and $\theta_{y}$ are the displacements and rotations (in the vertical $y z$ and $x z$ planes) of the foundation, and $B$ is a characteristic length (i.e., the foundation diameter or width), introduced for dimensional consistency (see Fig. 1).

To reproduce correctly some important features of the experimentally observed behavior of the foundation-soil system such as nonlinearity, irreversibility and dependence from past loading history, the constitutive equation for the macromodel must be 
formulated in rate-form:

$$
\dot{\boldsymbol{t}}=\mathcal{K}(\boldsymbol{t}, \boldsymbol{q}) \boldsymbol{d}
$$

where $\boldsymbol{d}:=\dot{\boldsymbol{u}}$ is the generalized velocity vector, $\mathcal{K}$ is the tangent stiffness of the system, depending on the system state and loading direction, and $\boldsymbol{q}$ is a pseudovector of internal variables accounting for the effects of previous loading history.

The properties of the stiffness matrix $\mathcal{K}$ are selected according to the basic features of observed behavior. To reproduce a rate-independent response, $\mathcal{K}$ must be positively homogeneous of degree zero with respect to the generalized velocity vector $\boldsymbol{d}$. In order to reproduce an inelastic behavior, $\mathcal{K}$ must depend on the loading direction $\boldsymbol{d} /\|\boldsymbol{d}\|$ (Kolymbas 1991).

In this work, the performance of two different macroelement models is assessed with respect to the analysis of the dynamic response of a $\mathrm{RC}$ bridge subject to earthquake loading. The first macroelement model is formulated within the framework of kinematic hardening elastoplasticity with prescribed bounding surface (Grange et al. 2009). The second macroelement model has been recently developed within the framework of the theory of hypoplasticity (Salciarini and Tamagnini 2009).

\section{THE ELASTOPLASTIC MACROELEMENT}

In the macromodels developed in the framework of the theory of elastoplasticity (Nova and Montrasio 1991; Martin and Houlsby 2001; Crémer et al. 2001; Grange et al. 2008), the constitutive equation is built starting from the fundamental assumptions of: i) elastic and plastic decomposition of the generalized velocity; ii) existence of a yield function $f(\boldsymbol{t}, \boldsymbol{q})$ in the generalized load space; iii) existence of a plastic potential function $g(\boldsymbol{t}, \boldsymbol{q})$ providing the plastic flow direction; iv) existence of a suitable hardening law for the internal variables; and, v) enforcement of Prager's consistency condition.

The resulting constitutive equation in rate form then reads:

$$
\begin{aligned}
\dot{\boldsymbol{t}} & =\mathcal{K}^{e p}(\boldsymbol{t}, \boldsymbol{q}) \boldsymbol{d} \quad \dot{\boldsymbol{q}}=\mathcal{H}(\boldsymbol{t}, \boldsymbol{q}) \boldsymbol{d} \\
\mathcal{K}^{e p} & :=\mathcal{K}^{e}-\frac{H(\dot{\gamma})}{K_{p}}\left\{\mathcal{K}^{e}\left(\frac{\partial g}{\partial \boldsymbol{t}}\right)\left(\frac{\partial f}{\partial \boldsymbol{t}}\right)^{T} \mathcal{K}^{e}\right\} \\
\mathcal{H} & :=\frac{H(\dot{\gamma})}{K_{p}} \boldsymbol{h}_{q}\left(\frac{\partial f}{\partial \boldsymbol{t}}\right)^{T} \mathcal{K}^{e}
\end{aligned}
$$

where $\mathcal{K}^{e}$ is the elastic stiffness matrix; $\boldsymbol{h}_{q}(\boldsymbol{t}, \boldsymbol{q})$ is the hardening function controlling the evolution of the internal variables with plastic displacements; $K_{p}$ is a strictly positive scalar given by:

$$
K_{p}:=\left(\frac{\partial f}{\partial \boldsymbol{t}}\right)^{T} \mathcal{K}^{e} \frac{\partial g}{\partial \boldsymbol{t}}-\left(\frac{\partial f}{\partial \boldsymbol{t}}\right)^{T} \boldsymbol{h}_{q}
$$

and $H(\dot{\gamma})$ is the Heaviside step function, equal to 1 if the plastic multiplier:

$$
\dot{\gamma}:=\frac{1}{K_{p}}\left(\frac{\partial f}{\partial \boldsymbol{t}}\right)^{T} \mathcal{K}^{e} \boldsymbol{d}
$$

is positive, and zero otherwise.

The particular elastoplastic macroelement model considered in this study is a kinematic hardening elastoplastic macroelement specifically developed for cyclic loading conditions by Grange et al. (2009). The yield function is given by the following equation:

$$
\begin{aligned}
f(\boldsymbol{t}, \boldsymbol{\tau}, \gamma, \rho)= & \left\{\frac{h_{x}}{a v^{c}(v-\gamma)^{d}}-\tau_{h x}\right\}^{2}+ \\
& \left\{\frac{m_{x}}{b v^{e}(v-\gamma)^{f}}-\tau_{m x}\right\}^{2}+ \\
& \left\{\frac{h_{y}}{a v^{c}(v-\gamma)^{d}}-\tau_{h y}\right\}^{2}+ \\
& \left\{\frac{m_{y}}{b v^{e}(v-\gamma)^{f}}-\tau_{m y}\right\}^{2}-\rho^{2}=0
\end{aligned}
$$

where, for a square footing:

$$
v=\frac{V}{V_{f}}, h_{\alpha}=\frac{H_{\alpha}}{V_{f}}, m_{\alpha}=\frac{M_{\alpha}}{B V_{f}} \quad(\alpha=x, y)
$$

are non-dimensionalized components of the generalized force vector; $V_{f}$ is the bearing capacity of the foundation under a vertical centered load; $B_{x}$ and $B$ is the footing size; $\gamma$ and $\rho$ are internal variables defining the size of the yield locus; $\tau$ is a kinematic internal variable defining the position of the yield locus in the generalized loading space; $a, b, c, d, e$ and $f$ are model constants controlling the shape of the yield locus. The failure locus of the foundation in the generalized loading space is found by setting $\boldsymbol{\tau}=\mathbf{0}$, and $\rho=\gamma=1$ in eq. (6).

As for the plastic potential function $g$, an associative flow rule is adopted in the $\left(h_{x}, h_{y}, m_{x}, m_{y}\right)$ hyperplane, while, in agreement with available experimental observations, a non-associative flow rule is defined in the $\left(h_{x}, v\right),\left(h_{y}, v\right),\left(m_{x}, v\right)$ and $\left(m_{y}, v\right)$ planes. A detailed description of the plastic potential function and of the evolution equations for the internal variables $\rho, \gamma$ and $\tau$ is provided in Grange (2008) and Grange et al. (2008).

A specific feature of this model is in the possibility of taking into account the irreversible displacements 
associated to the uplift of the foundation which takes place at high values of the load eccentricity. However, as uplift has not been considered in this work, the interested reader is referred to Grange et al. (2009) for further details.

\section{THE HYPOPLASTIC MACROELEMENT}

In the development of a hypoplastic macrolement, Salciarini and Tamagnini (2009) have assumed from the outset that the tangent stiffness tensor appearing in eq. (1) possesses the following basic structure:

$$
\mathcal{K}=\mathcal{L}(\boldsymbol{t}, \boldsymbol{q})+\boldsymbol{N}(\boldsymbol{t}, \boldsymbol{q}) \boldsymbol{\eta}^{T} \quad \boldsymbol{\eta}:=\frac{\boldsymbol{d}}{\|\boldsymbol{d}\|}
$$

Differently from elastoplasticity, the tangent stiffness $\mathcal{K}(\boldsymbol{t}, \boldsymbol{q}, \boldsymbol{\eta})$ varies continuously with the direction $\boldsymbol{\eta}$ of the generalized velocity. This property is known as incremental nonlinearity (see, e.g., Tamagnini et al. 2000), and is the key to the modeling of irreversibility of the model response.

The construction of a specific hypoplastic macroelement requires the definition of the constitutive functions $\mathcal{L}(\boldsymbol{t}, \boldsymbol{q})$ (a $5 \times 5$ matrix) and $\boldsymbol{N}(\boldsymbol{t}, \boldsymbol{q})$ (a 5 -dimensional vector). Upon load reversal, the incremental response of the hypoplastic macroelement is assumed to be almost elastic:

$$
\dot{\boldsymbol{t}}=\boldsymbol{K}^{e} \boldsymbol{d} \quad \mathcal{K}^{e}:=\operatorname{diag}\left\{k_{v} ; k_{h} ; k_{h} ; k_{m} ; k_{m}\right\}
$$

where $\mathcal{K}^{e}$ is the elastic stiffness matrix of the elastoplastic macroelement, and $k_{v}, k_{h}$ and $k_{m}$ define the vertical, horizontal and rotational stiffnesses of the foundation-soil system. Thus, the matrix $\mathcal{L}$ can be written as follows (Salciarini and Tamagnini 2009):

$$
\mathcal{L}=\frac{1}{m_{R}} \mathcal{K}^{e}=\frac{1}{m_{R}} \operatorname{diag}\left\{k_{v} ; k_{h} ; k_{h} ; k_{m} ; k_{m}\right\}
$$

where $m_{R}$ is a material constant.

The constitutive function $\boldsymbol{N}$ is obtained following the approach proposed by (Niemunis 2002), according to which $N$ can be expressed as:

$$
\boldsymbol{N}\left(\boldsymbol{t}, V_{f}\right)=-Y\left(\boldsymbol{t}, V_{f}\right) \mathcal{L} \boldsymbol{m}(\boldsymbol{t})
$$

where $0 \leq Y\left(\boldsymbol{t}, V_{f}\right) \leq 1$ is a scalar loading function and $\boldsymbol{m}(\boldsymbol{t})$ is a 5 -dimensional unit vector.

In the particular case of continued loading along a straight path of sufficient length, eq. (8) and (11) yield:

$$
\dot{\boldsymbol{t}}=\mathcal{L}\{\boldsymbol{d}-Y \boldsymbol{m}\|\boldsymbol{d}\|\}
$$

The scalar function $0 \leq Y\left(\boldsymbol{t}, V_{f}\right) \leq 1$ controls the degree of nonlinearity of the model response. If $Y=0$, eq. (12) reduces to a linear relation between $\dot{t}$ and $\boldsymbol{d}$. When $Y\left(\boldsymbol{t}, V_{f}\right) \rightarrow 1$ the system reaches an ultimate failure state $(\dot{t}=0)$ for a collapse mechanism characterized by:

$$
\boldsymbol{\eta}=\boldsymbol{m}
$$

Thus $\boldsymbol{m}$ can be identified as the direction of the generalized velocity vector at bearing capacity failure (i.e., unconfined "plastic flow" direction).

The loading function $Y$ can be defined starting from a 5-dimensional generalization of the failure locus proposed by Nova and Montrasio (1991):

$$
\begin{aligned}
f(\boldsymbol{t})= & \left\{\frac{h_{x}}{\mu}\right\}^{2}+\left\{\frac{m_{x}}{\psi}\right\}^{2}+\left\{\frac{h_{y}}{\mu}\right\}^{2} \\
& +\left\{\frac{m_{y}}{\psi}\right\}^{2}-v^{2}(v-1)^{2 \beta}=0
\end{aligned}
$$

while the plastic flow direction $\boldsymbol{m}$ can be derived from the plastic potential function of Nova and Montrasio (1991):

$$
\begin{aligned}
g(\boldsymbol{t})= & \left\{\frac{h_{x}^{\prime}}{\lambda_{h} \mu}\right\}^{2}+\left\{\frac{m_{x}^{\prime}}{\lambda_{m} \psi}\right\}^{2}+\left\{\frac{h_{y}^{\prime}}{\lambda_{h} \mu}\right\}^{2} \\
& +\left\{\frac{m_{y}^{\prime}}{\lambda_{m} \psi}\right\}^{2}-\left(v^{\prime}\right)^{2}\left(v^{\prime}-1\right)^{2 \beta}
\end{aligned}
$$

in which the nondimensional variables $v^{\prime}, h_{x}^{\prime}, h_{y}^{\prime}, m_{x}^{\prime}$ and $m_{y}^{\prime}$ are obtained from the corresponding quantities of eq. (7) by replacing $V_{f}$ with $V_{g}$, a dummy variable determined from the condition $g\left(t, V_{g}\right)=0$.

Finally, in order to describe the foundation-system response under both monotonic and cyclic loading conditions, the hypoplastic macroelement is equipped with the following set of internal state variables:

$$
\boldsymbol{q}:=\left\{V_{f}, \boldsymbol{\delta}\right\}
$$

where $V_{f}$ is again the bearing capacity of the foundation under a vertical centered load, and $\delta$ is a vectorial quantity - the "internal displacement" vector which keeps track of the previous displacement history, mimicking the concept of intergranular strain introduced by (Niemunis and Herle 1997) for continuum hypoplasticity. The details of the evolution equations for these internal variables are provided in Salciarini and Tamagnini (2009).

\section{THE PROBLEM CONSIDERED}

The problem considered is a four-span RC bridge, whose geometry is shown in Fig. 2. This particular structure has been studied at the European research centre ELSA (JRC Ispra), where a series of 1 to 2.5 scale models of the bridge piers have been subject to pseudo-dynamic tests, see Pinto et al. (1996).

The three piers are made of reinforced concrete with a hollow rectangular section shape. The bridge 


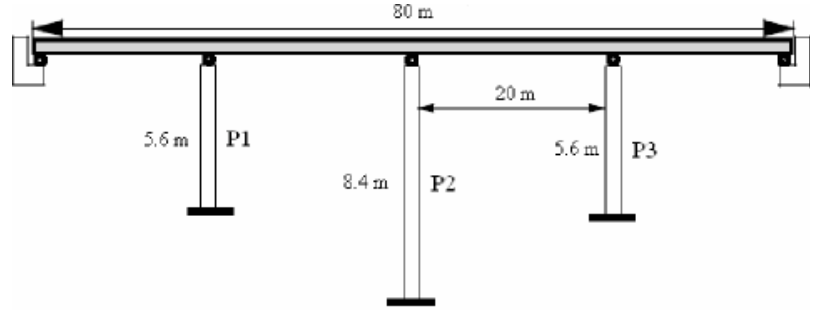

Figure 2: Plan view of the bridge.

\begin{tabular}{cccccc}
\hline & $\begin{array}{c}A \\
\left(\mathrm{~m}^{2}\right)\end{array}$ & $\begin{array}{c}I_{x} \\
\left(\mathrm{~m}^{4}\right)\end{array}$ & $\begin{array}{c}I_{y} \\
\left(\mathrm{~m}^{4}\right)\end{array}$ & $\begin{array}{c}I_{z} \\
\left(\mathrm{~m}^{4}\right)\end{array}$ & $\begin{array}{c}J \\
\left(\mathrm{~m}^{4}\right)\end{array}$ \\
\hline \hline Deck & 1.11 & 0.13 & - & 2.26 & 2.39 \\
Piers & 0.66 & 0.056 & 0.19 & - & 0.20 \\
\hline
\end{tabular}

Table 1: Geometrical properties of structural elements.

deck is composed of hollow prestressed concrete beams. Some geometrical characteristics of the piers and beams sections are given in Tab. 1 .

The FE model of the structure is shown in Fig. 3. Non-linear Timoshenko multifiber beam elements have been adopted to reproduce the behaviour of the piers (Kotronis and Mazars 2005). In detail, 40 concrete fibers and 80 steel fibers (representing the reinforcement bars at their actual position) have been used for each section. The mesh is refined at the base of the piers where inelastic behavior is more likely to occur. As for the prestressed concrete deck elements, linear elastic behavior has been assumed. The inertial characteristics of the structural elements have been simulated by means of lumped masses, as shown in Fig. 3 . The material constants adopted for pier and deck elements are given in Grange (2008).

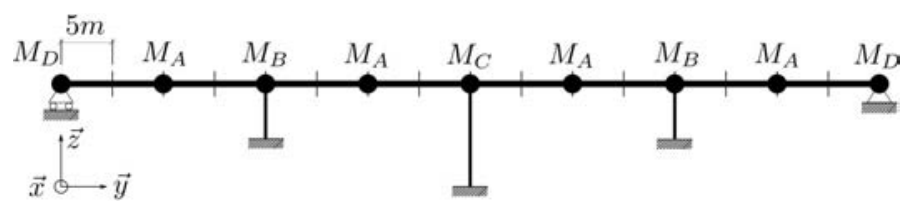

Figure 3: FE model of the bridge.

In order to validate the FE model, a first comparison of the numerical and experimental results for the small-scale bridge model, under the hypothesis of fixed base has been presented in (Grange et al.), (Grange et al.). In this paper, the foundations of the three piers have been modeled using the two macroelements discussed in Sect. 2 and 3. The material parameters adopted for the elastoplastic macroelement are summarized in Tab. 2. They can be considered appropriate for a foundation resting on a medium-dense sand. The material constants for the hypoplastic macroelement have been selected by matching the predictions of the two macroelements

\begin{tabular}{cccccc}
\hline $\begin{array}{c}k_{v} \\
(\mathrm{MN} / \mathrm{m})\end{array}$ & $\begin{array}{c}k_{h} \\
(\mathrm{MN} / \mathrm{m})\end{array}$ & $\begin{array}{c}k_{m} \\
(\mathrm{MN} / \mathrm{m})\end{array}$ & $\begin{array}{c}V_{f} \\
(\mathrm{MN})\end{array}$ \\
\hline \hline 298.68 & 244.37 & \multicolumn{1}{c}{108.65} & 11.26 \\
\hline \hline$a$ & $b$ & $c$ & $d$ & $e$ & $f$ \\
$(-)$ & $(-)$ & $(-)$ & $(-)$ & $(-)$ & $(-)$ \\
\hline \hline 0.48 & 0.33 & 1.00 & 0.95 & 1.00 & 0.95 \\
\hline
\end{tabular}

Table 2: Material constants of the elastoplastic macroelement.

\begin{tabular}{ccccccc}
\hline $\begin{array}{c}\mu \\
(-)\end{array}$ & $\begin{array}{c}\psi \\
(-)\end{array}$ & $\begin{array}{c}\beta \\
(-)\end{array}$ & $\begin{array}{c}\lambda_{h} \\
(-)\end{array}$ & $\begin{array}{c}\lambda_{m} \\
(-)\end{array}$ & $\begin{array}{c}\kappa \\
(-)\end{array}$ \\
\hline \hline 0.48 & 0.33 & 0.95 & 1.75 & 1.50 & 0.25 \\
\hline$\xi$ & $m_{R}$ & $m_{T}$ & $R$ & $\beta_{r}$ & $\chi$ \\
$(\mathrm{MN} / \mathrm{m})$ & $(-)$ & $(-)$ & $(\mathrm{mm})$ & $(-)$ & $(-)$ \\
\hline \hline 0.0 & 1.1 & 1.05 & 5.0 & 1.0 & 1.5 \\
\hline \hline
\end{tabular}

Table 3: Material constants of the hypoplastic macroelement.

on both monotonic and cyclic loading paths. The result of this calibration procedure is shown in Tab. 3 .

The seismic input adopted in the FE simulations is shown in Fig. 4. It is an artificial accelerogram, applied in the $x$ direction, consistent with the 5\% damping response spectrum provided by Eurocode 8 for a soil of Class B, with a peak horizontal acceleration of $0.35 \mathrm{~g}$. In the FE analyses, the accelerogram has been scaled by multiplying the accelerations by 2.5 and dividing the time scale by the same factor, in order to respect the similitude laws. The same input motion is applied at the base of the piles and at the bridge abutments.
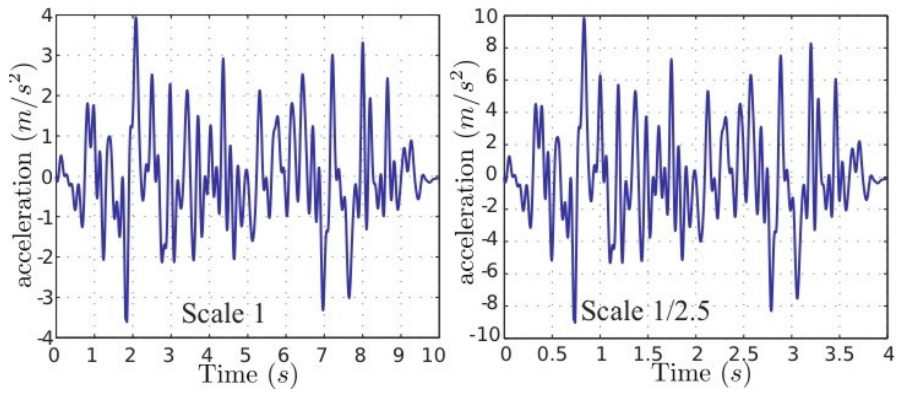

Figure 4: Original and scaled accelerograms of the imposed seismic excitation.

\section{RESULTS OF FE SIMULATIONS}

Some results of the FE simulations performed with the two macroelement models are shown in Fig. 5 to 10 . To assess the influence of soil-foundation deformability, the results of full SFSI analyses are also compared to those obtained assuming the soil as perfectly rigid (i.e., zero displacement and rotations at the base of the piers). 
The computed load-displacement curves for the pier foundations are shown in Fig. $5\left(H_{x} v s . u_{x}\right)$ and 6 $\left(M_{y} v s . \theta_{y}\right)$. Although the hypoplastic model tends to predict somewhat smaller horizontal displacements, the agreement between the two numerical solutions appears quite good.
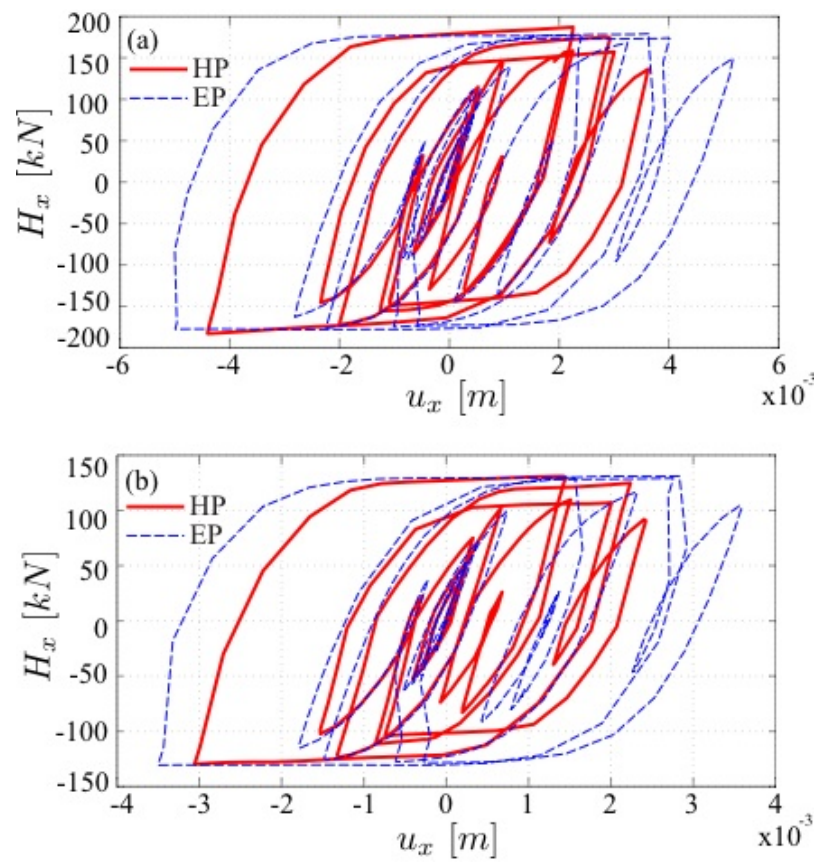

Figure 5: Horizontal force $v s$. horizontal displacement at the foundations: a) piers $\mathrm{P} 1$ and $\mathrm{P} 3$; b) pier P2.
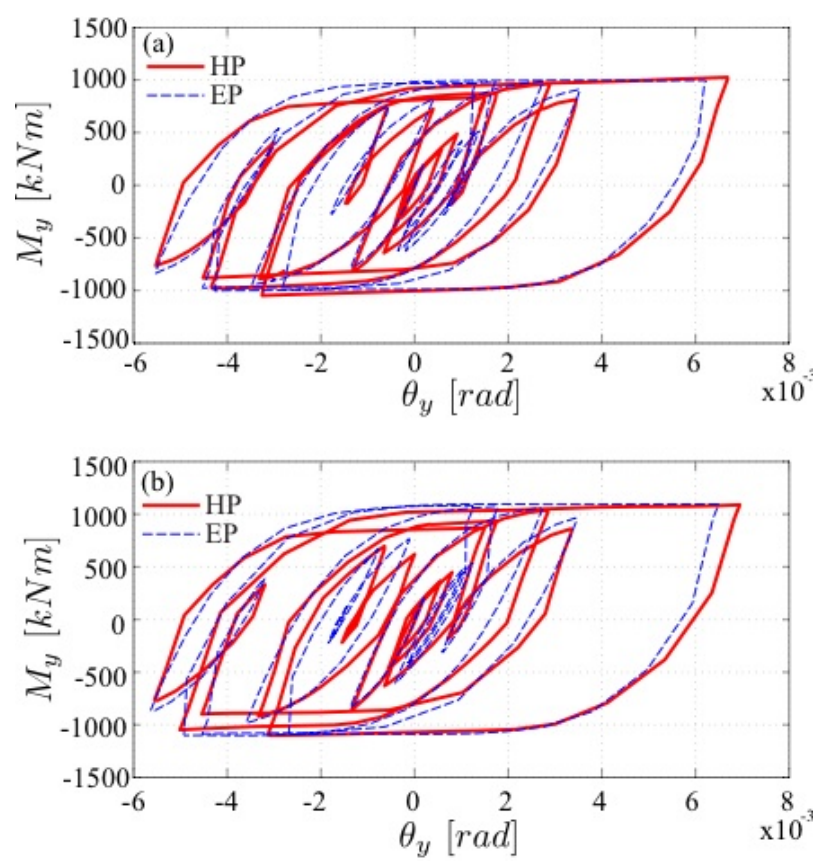

Figure 6: Rocking moment vs. rotation at the foundations: a) piers $\mathrm{P} 1$ and $\mathrm{P} 3$; b) pier $\mathrm{P} 2$.

This is confirmed by the time histories of horizontal forces and moments at the foundations, as shown in
Fig. 7 and 8 for pier P2. The results obtained with the two macroelements are almost coincident, whereas forces and moments obtained under the hypothesis of fixed base are much larger.

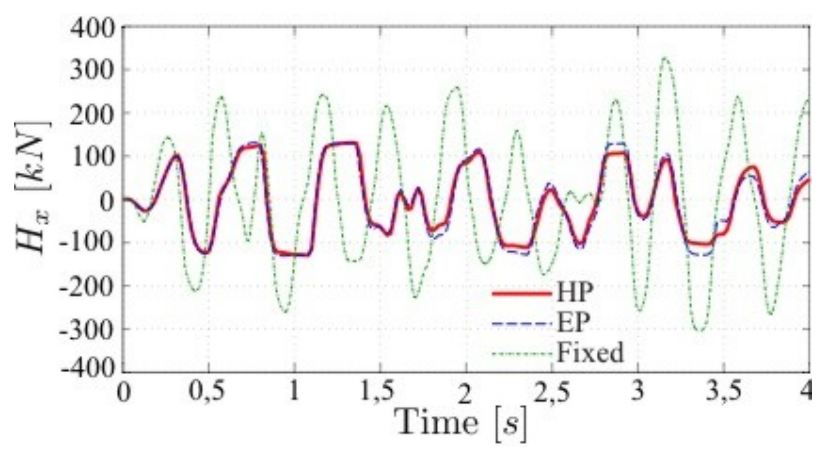

Figure 7: Time-history of horizontal force at the foundation of pier $\mathrm{P} 2$.

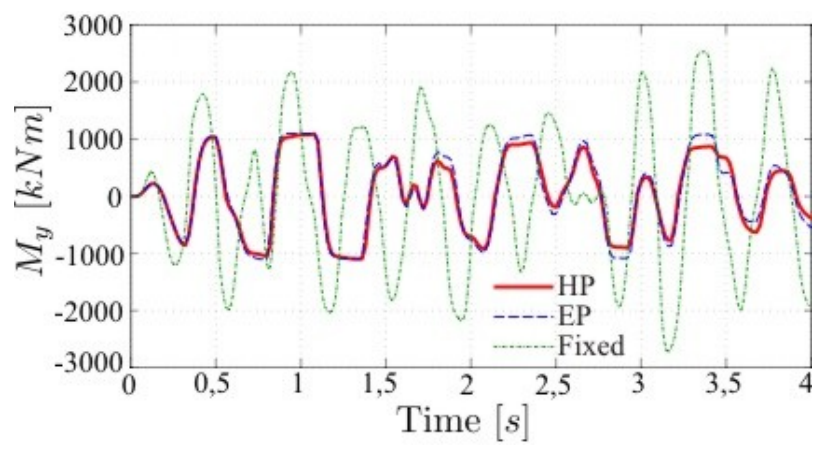

Figure 8: Time-history of rocking moment at the foundation of pier $\mathrm{P} 2$.

It is interesting to note that in the particular case considered, the incorporation of the deformable macroelements in the FE analysis does not affect significantly the magnitude of horizontal displacements at the top of the piers, as shown in Fig. 9. This is a consequence of the fact that, in the fixed base case, the bending moments at the base of the piers are so large that the piers enter into the non-linear regime, and undergo significant plastic rotations, as demonstrated by the moment-curvature diagram for the base of pier P2, shown in Fig. 10. However, for different soil conditions or higher earthquake accelerations, a significant underestimation of the displacements at the top of the piles can occur if the deformability of the soil is not properly taken into account (Grange et al. 2009), (Grange et al. 2010).

Finally, Fig. 11 shows the time-histories of vertical displacements accumulated at the foundation of pier P2, for the two macroelements. Differently from computed horizontal displacements and rotations, in this case the response of the two macroelements is quite different. While the elastoplastic analysis predicts very small permanent settlements (about $1 \mathrm{~mm}$ ), 
the hypoplastic simulation yields a much larger permanent settlement (about $6 \mathrm{~mm}$ ). This is most likely due to the different nature of the plastic potential functions adopted by the two models in the $H_{x}: V$ and $M_{y} / B: V$ planes.

\section{CONCLUDING REMARKS}

In this work, two recently developed macroelements for shallow foundations have been used to model the soil-foundation response in the seismic analysis of a RC bridge. In spite of the different mathematical structure of the two models, the results obtained in the two cases are surprisingly similar, both in terms of computed displacements and structural loads. The only exception is represented by the way the two macroelements predict a continuous accumulation of vertical settlements of the foundation under the earthquake excitation.

It is worth noting that the good agreement between the computed cyclic response of the foundations provided by the two macroelements is mostly due to the presence in the set of internal state variables of a vectorial quantity (the back-stress in the elastoplastic model; the internal displacement in the hypoplastic model) which takes into account the effects of the previous loading history.

Finally, the comparison with the results obtained under the hypothesis of rigid soil indicates that this last assumption may lead to a significant overestimation of computed structural loads. Moreover, a proper consideration of the soil-foundation deformability is a key factor in the proper estimation of the displacements experienced by the structure under the seismic action.

\section{REFERENCES}

Crémer, C., A. Pecker, and L. Davenne (2001). Cyclic macro-element for soil-structure interaction: material and geometrical non-linearities. Int. J. Num. Anal. Meth. Geomech. 25, 1257-1284.

Grange, S. (2008). Modélisation simplifiée $3 D$ de l'interaction sol-structure: application au génie

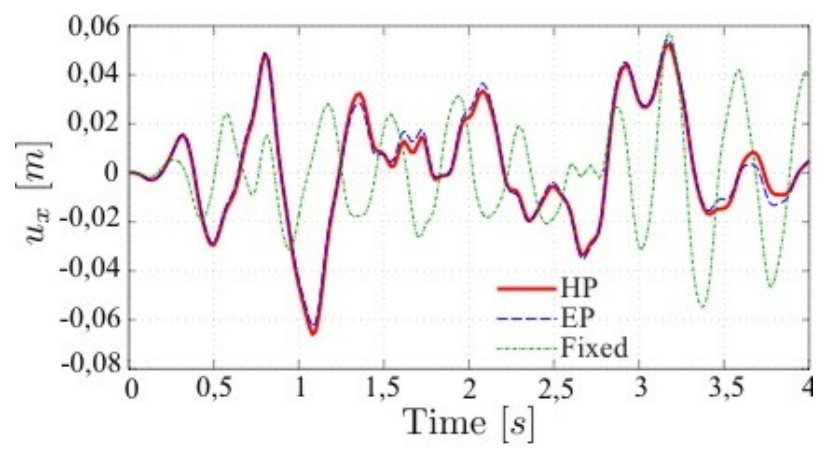

Figure 9: Time-history of horizontal displacement at the top of pier $\mathrm{P} 2$.

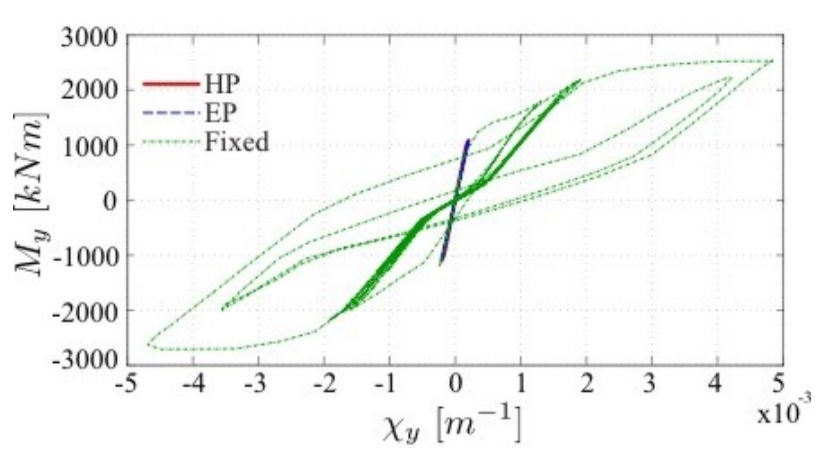

Figure 10: Bending moment vs. curvature at the base of pier $\mathrm{P} 2$.

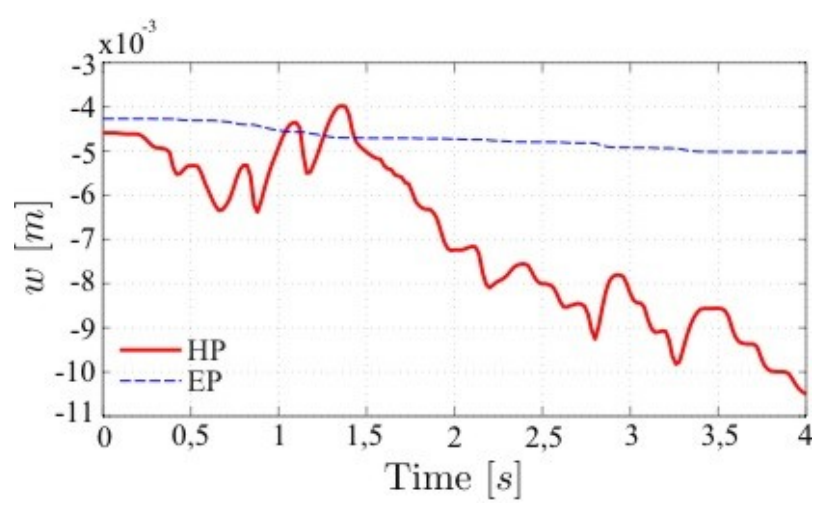

Figure 11: Time-history of vertical displacement at the foundation of pier $\mathrm{P} 2$.

parasismique. Ph. D. thesis, INP Grenoble. http://tel.archives-ouvertes.fr/tel-00306842/fr.

Grange, S., L. Botrugno, P. Kotronis, and C. Tamagnini (2009). The effect of soil-structure interaction on a reinforced concrete bridge. In G. Pande, S. Pietruszczak, C. Tamagnini, and R. Wang (Eds.), Computational Geomechanics - COMGEO I. Intl. Centre for Computational Engineering, Rhodes.

Grange, S., L. Botrugno, P. Kotronis, and C. Tamagnini (2010). On the influence of soil structure interaction on a reinforced concrete bridge. Earthquake Engineering and Structural Dynamics. (In print).

Grange, S., P. Kotronis, and J. Mazars (2008). A macroelement for a circular foundation to simulate $3 \mathrm{~d}$ soil-structure interaction. Int. J. Num. Anal. Meth. Geomech. 32, 1205-1227.

Grange, S., P. Kotronis, and J. Mazars (2009). A macroelement to simulate $3 \mathrm{~d}$ soil-structure interaction considering plasticity and uplift. Int. Journal of Solids and Structures 46, 3651-3663.

Kolymbas, D. (1991). An outline of hypoplasticity. Archive of Applied Mechanics 61, 143-151.

Kotronis, P. and J. Mazars (2005). Simplified modelling strategies to simulate the dynamic behaviour of $\mathrm{r} / \mathrm{c}$ walls. Journal of Earthquake Engineering 9(2), 285-306.

Martin, C. M. and G. T. Houlsby (2001). Combined 
loading of spudcan foundations on clay: numerical modelling. Géotechnique 51, 687-700.

Niemunis, A. (2002). Extended Hypoplastic Models for Soils. Habilitation Thesis, Bochum University.

Niemunis, A. and I. Herle (1997). Hypoplastic model for cohesionless soils with elastic strain range. Mech. Cohesive-Frictional Materials 2, 279-299.

Nova, R. and L. Montrasio (1991). Settlements of shallow foundations on sand. Géotechnique 41, 243256.

Pinto, A., G. Verzeletti, P. Pegon, G. Magonette, P. Negro, and J. Guedes (1996). Pseudo Dynamic Testing of Large-Scale R/C Bridges. HMC Grant Holder, Report EUR 16378 EN, JRC Ispra, Italy.

Salciarini, D. and C. Tamagnini (2009). A hypoplastic macroelement model for shallow foundations under monotonic and cyclic loads. Acta Geotechnica 4(3), 163-176.

Tamagnini, C., G. Viggiani, and R. Chambon (2000). A review of two different approaches to hypoplasticity. In D. Kolymbas (Ed.), Constitutive Modelling of Granular Materials, pp. 107-145. Springer, Berlin. 